\title{
Introducing the Canadian Design Research Network
}

\author{
Robert Woodbury and Douglas MacLeod \\ Canadian Design Research Network \\ Simon Fraser University \\ Central City \\ 250 - 13450 102nd Avenue \\ Surrey, BC V3T OA3 \\ rw@sfu.ca dmacleod@cdrn.ca
}

\begin{abstract}
The Canadian Design Research Network (CDRN) is a consortium of academic institutions and industrial partners working together to improve design outcomes in Canadian society through research in design. The network is composed of specialized research clusters associated with major design schools across Canada and includes the key disciplines of architecture, landscape architecture, engineering, urban design, planning, industrial design, interaction design and buman-computer interaction. The CDRN works collaboratively across disciplines, and in particular, with policy makers and computer scientists to foster a shared understanding of the concerns, perspectives and methodologies of all stakeholders in the design process
\end{abstract}

\section{Introduction}

The Canadian Design Research Network (CDRN) is a new consortium of academics and partners from the private, public and NGO sectors working together to improve design outcomes in Canadian society through research in design.

Its main aims are to support its members in conducting world class design research, to engage academia and its receptor communities in strategic issues in design research, to assist knowledge and technology transfer between academia and receptor communities, to develop needed infrastructure for design research, and to improve the quality of design education by transferring research results to the classroom, the studio, the factory and the construction site.

The CDRN has a particular focus on designing for people in all of their contexts. Successful designs must be both technologically sound and readily usable. Successful design work is necessarily multidisciplinary, yet education and research occurs largely in focused disciplines. The CDRN aims to foster the development and maturation of the discipline of design by networking across both distance and discipline. Both are necessary. Canada is large and those who have made serious study of design are distributed across the country. They are also distributed within their institutions in such schools as design, architecture, engineering, computer science, environmental design, construction and landscape architecture.

The intent of the CDRN is to bring together these different disciplines, create an integrated approach to design research and share the results with both the design professions and the general public.

\section{Socio-Economic Context}

"Design has emerged as one of the world's most powerful forces. It has placed us at the beginning of an new period of human possibility, where all economies and ecologies are becoming global, relational, and interconnected."

Bruce Mau Massive Change: The Future of Global Design (2005)

The Massive Change Exhibition, shown at the Vancouver Art Gallery and the Toronto Art Gallery of Ontario, interprets design as a transformative force in society. Experienced by hundreds of thousands of people, this exhibition has changed Canadian public perception of this crucial source of social and economic benefits.

Research is an integral part of the design enterprise. It seeks to understand and improve design and its outcomes. It returns value in many ways. The theory, algorithms and initial implementations of the 
computer tools now essential in design practice largely originated in universities, in government labs such as NASA and in corporate research labs such as those of General Motors, Xerox Parc and IBM. Companies such as Alias Systems Corporation have relied on this basic research in developing systems used in the design industry. Universities often lead industry in applying new computational techniques to design and in prototyping new design ideas prior to acceptance in the market. Researchers studying design processes have developed insights and methods used in industrial design processes, particularly in the area of new technology. Strongly linked with design is visualization, of both physical reality and patterns in data. Research in visualization includes both new theories and systems to represent complex data sets. Design is by definition an applied discipline - it studies what people make, how things are conceived and made and how people use made things. Design research reflects this applied focus. It has a long history of using design tools and ideas in service to such receptor communities as software companies, educational institutions, non-profit organizations, museums and regional governments and design firms such as industrial designers, interaction designers, architects, urban designers and landscape architects.

In recent years technology has advanced more quickly than usability. The results affect us every day. Interactive devices such as cell phones, video cameras and microwave ovens have notoriously difficult controls. Computer software and systems often hinder the work that they are intended to help. Poorly designed hospital systems and procedures sometimes cost lives. Inflexible building designs increase cost of ownership and organizational effectiveness. Designs that are effective for people return real value to their users and the firms that create, produce and market such work. Research in designing for people has become an important, though distributed, academic discipline. Over the last generation much has been learned about how people use designs, how designers create designs, how designs become successful in the marketplace and how to support more effective and human-centered design practices.

In universities, the study of design is organized around the things designed. For example, architecture, the engineering disciplines, industrial design and interface design each focus on a specific class of artifacts. This is done for good reason: professional expertise requires deep knowledge of the thing being designed and much of every designer's education is spent learning about the artifacts themselves. Yet there is much in common among those disciplines and much that they can learn from each other. An unfortunate result of this division of design by artifact class is that those academics whose research is concerned with the process of design itself tend to be isolated and sparsely distributed across a nation. Graduate students are hurt by this dispersion --- it is hard for students to develop insight or community beyond their specialization. There is much to be gained by collaboration.

Worldwide, engineering and design schools have had to accommodate an increasingly complex world. Technology is becoming both more complex of itself and more embedded into society. As the planet approaches natural limits of resources and population, design must also deal with the impact it creates. It seems very clear that prior disciplinary boundaries work against success in complex design situations. Internationally, several engineering and design schools have specifically developed aspects of their programs to deal with the social, technological and process complexities that so characterize contemporary design. For example, Carnegie Mellon University's history of design research and education program spans five of its colleges, nearly thirty years, and several large centres (DRC, EDRC, ICES). It has also spawned a related department (Engineering and Public Policy). A crucial issue for design, across academia and practice, is to learn to deal with complexity. In the Canadian context, this requires a networked approach.

Canadian industry too suffers from a sparse distribution of design expertise across organizations. This is exacerbated by design projects themselves. The multi-firm, multi-discipline design project is the norm and the design industries show less corporate concentration than others. Designers in industry face particular difficulties in keeping abreast of developments in design, and industry can only embark on short-term research and development projects because it lacks the necessary market and corporate concentration.

\section{Network Focus}

Design must respond to the rapid technological and social change in contemporary society. There are many key issues driving these changes. Of these the CDRN has selected six critical themes as most useful to its receptor communities. Each has been chosen for both its social importance and its impact on design research.

Sustainability in design aims to maximize positive design performance and minimize deleterious environmental effects. It is a critical aspect of the very large and multidisciplinary issues that affect our global environment.

Advanced design technologies amplify human effort by supporting the discovery of new methods of 
design practice and managing the huge increase in the complexity of design information and tasks.

Fabrication addresses the increasing capability of computer numerical control (CNC) machinery to realize digitally represented designs. By enabling custom manufacture at competitive cost this new technology transforms the potential of design.

Interactive technologies include any device in which a computer mediates the user experience of the technology. Currently there is an explosion in new products and services in this field, but design and manufacturing processes have not yet been transformed to adequately address the innovative applications afforded by such technologies.

Design visualization and simulation provides innovative tools and new ways for researchers, historians, anthropologists, archeologists, architects, environmental and urban planners and students to conceptualize, study and learn about Canadian historical events and cultural places. Threedimensional representations afford learning above and beyond what images and print can provide by facilitating the exploration of temporal, spatial and causal relationships inherent in historical events and cultural stories.

Visual analytics encompasses designs for and the science of analytical reasoning using interactive visual interfaces. It identifies a crucial future area for design - the unprecedented scale and complexity of information in areas such as security, disaster relief, health sciences and complex systems which demands the development of an entire new class of analytical tools. Through its focus on the applied psychology of complex tasks, visual analytics provides a scientific basis for many of the other themes.

\section{Network Activities}

In March of 2006 the CDRN became part of the Networks of Centres of Excellence, New Initiatives Program. This will provide four years of funding in order to bring design researchers and their receptor communities together.

Networks of Centres of Excellence are unique partnerships among universities, industry, government and not-for-profit organizations aimed at turning Canadian research and entrepreneurial talent into economic and social benefits for all Canadians. The intent of the New Initiatives program is to find and foster synergy across its member disciplines in academia, industry and the public sector. Specifically the CDRN will use this funding to connect design research to its receptor communities and to aid in the development and retention of highly qualified personnel. To achieve these goals the network will be conducting a variety of focused events and communication activities centred on the network's research themes and including:

Theme events. Each event will comprise small scale preliminary seminars at multiple locations, placement of graduate student interns in key industrial settings, a multi-day hands-on residential workshop for academia and industry on the state of the art in each research theme, an academic planning meeting for researchers, a networking event for graduate students and receptor communities, a professional symposium, technology demonstrations and an online exhibition of the event. Six such events, one on each of the themes, are planned. In the area of advanced design technologies the CDRN has already conducted an intensive 3-day workshop in Toronto on parametric modeling as part of the Subtle Technologies Conference.

Dissemination and communication of design research and novel practice through online resources. There are many fora for design research and practice through the conventional publication channels of professional and academic journals and conferences. Our communication strategy is to foster debate on design research by partnering with receptor communities to assist them in recording and publishing design-related material online. Current plans are to employ two new media developed by members of the network. Architecture Radio is a nonprofit organization that exists to serve the design community through the recording and dissemination of events such as key lectures that would otherwise be lost to the larger design community. A $\bullet \mathrm{VI} \bullet \mathrm{RE}$ is an online gallery and public discourse system for cultural and designed artifacts. A $\bullet \mathrm{VI} \bullet \mathrm{RE}$ uses a wiki to support discourse. Wikis are community authoring environments, of which the most well-known example is Wikipedia, a collaborative, free open-content, community-reviewed encyclopedia. The CDRN will build an extensive illustrated design research wiki using the $\mathrm{A} \bullet \mathrm{VI} \bullet \mathrm{RE}$ environment.

Graduate student mobility grants. These grants will foster the development of highly qualified personnel who understand design issues, practices and technologies in their receptor communities and beyond their home discipline. Such knowledge is essential in the increasingly multi-disciplinary and multi-sectoral discipline of design. The grants will support the incremental costs of travel and accommodation for extended visits to receptor organizations and research labs. Either the researcher (through a research assistantship) or the receptor (through an internship) will bear the regular support costs for the students involved. 
Research methodology transfer. The aim of this activity is to provide training opportunities for graduate students and researchers across Canada to share and learn about research methodologies that have been applied across disciplines and contexts, to reflect on the appropriate application of these methodologies, and to advance the field through refining and adapting methodologies from other disciplinary areas. For example, action research and participatory design are two aligned, yet distinct methodological perspectives that may be embraced by the design research community and adapted to meet local needs. Another example is the use of experimental methods in the evaluation of research using design prototype methods. The articulation and clear communication of these methodologies is essential to the establishment of design research as a distinct and credible approach in its own right.

\section{Expected Impacts}

Each of the project's themes is of strategic importance to Canadian society; each has critical unsolved research questions; each is a current focus in Canadian design research; and each contributes substantively and methodologically to other themes. To reiterate, the six themes are: sustainability - how design contributes to the wise use of resources and environment; advanced design technologies - new systems that support design work; fabrication - new processes and systems for the rapid realization of designs; interaction - how people use digital technology; design visualization and simulation using digital technology to interpret and communicate Canadian culture; and visual analytics - the design and science of analytical reasoning facilitated by new interactive visual interfaces.

\section{Why Organize Around Themes?}

The network's organization around these themes reflects the necessity that highly qualified personnel in design acquire both disciplinary depth and interdisciplinary breadth. The themes provide the depth: each is a current and critical issue in design and an appropriate and current area for thesis work. Intertheme relations provide both breadth and critical transfer of ideas and methods. This logic is mirrored in receptor communities, which have direct concerns for such things as taking advantage of advanced design technologies, but may be unaware of the implications of such technologies on, for example, energy efficiency or the new capabilities implied by rapid fabrication of designs.

\section{Highly qualified personnel}

In spite of the clear need for disciplinary focus, it seems that existing disciplinary boundaries can work against success in developing highly qualified personnel in design. The reason for this is methodological. Research questions that arise in design often require methods from other disciplines, or combinations of methods across disciplines. For example, in advanced technologies the key technological questions and methods are from constraint satisfaction and simulation. Understanding how designers actually work with such systems is currently best answered through largely ethnographical methods. Students working solely (or independently) within one of these traditions run the risk of doing work that is either technologically sophisticated but difficult to use, or easy to use, but not relevant. By sustaining structured exchanges across disciplinary traditions, the CDRN will foster a new cohort of highly qualified personnel able to address the complex state of current design research.

\section{Cross-theme impacts}

Each theme was carefully chosen to complement the others, in both the theme content and in research methods used. For each theme we list one particularly important example. Sustainability makes extensive use of multi-criteria decision methods, which are important, but largely absent, in most advanced design technology research. Advanced design technologies provide new representations and algorithms that inform design visualization and simulation. Fabrication technologies make possible the physical generation of a wide range design possibilities, which affords new methods of user-centered design processes for interactive technologies. Design visualization and simulation relies on ethnographic studies to understand how groups respond to new technological capabilities. These methods and their results are important in designing new technology in many forms. The usability and design methods created by researchers in interactive technologies provide design methods for the creation of new visual analytical displays. Finally visual analytics is a new applied science of human perception, cognition and action that informs all design fields.

\section{Receptor Communities.}

Design is interdisciplinary and there is much in common across its areas, yet specific research questions and projects typically focus on particular applications.

By assisting in coordinating diverse research initiatives, the CDRN will assist receptor communities in accessing design research expertise, will decrease 
redundancy and will increase potential for stronger advances in the overall field of design research.

Currently these receptor communities include cities such as Ottawa, Quebec City and Kitchener; academic institutions from Dalhousie University to the University of British Columbia; NGO's from CANARIE to the Friends of Fort York; companies from Canada, France and the United States; and designers from across the country.

The practitioners include internationally known designers and researchers such as Bruce Mau and Ray Cole as well as innovative, emerging designers and researchers such as Shane Williamson and Brian Lilley. The CDRN has not only garnered the support of large, international corporations such as Autodesk/Alias but also of SME's such as I-mmersion Studios. Finally it includes two important vehicles for dissemination - Canadian Architect Magazine, Canada's foremost design journal and Architecture Radio, an innovative approach to sharing information about design through web-based radio broadcasts.

This breadth is important for not only does it reflect the essential diversity of contemporary Canada with its emphasis on inclusion but it also seeds the ground with multiple receptor communities so that the network can develop and grow over its four year mandate. The CDRN has embarked on a program of active recruitment to expand its membership and reach our to additional receptor communities. Community building is the key to realize the network's objectives.

\section{Relation to the Canadian Design Engineering Network}

The network has been multidisciplinary from its very inception. The founding members include architects, industrial designers, urban designers, interaction designers, planners, computer scientists, landscape architects, historians, artists, engineers and specialists in computer-human interaction, computer graphics and virtual reality. The value of such an approach has been proven again and again in projects such as MACI (Multimedia Advanced Computational Infratructure) and the $3 \mathrm{DWeb}$ project which also brought together the worlds of design and technology to achieve more than either group could accomplish in isolation. Based on this experience, it is possible to assert that a multidisciplinary approach can have both incremental and transformative value.

Similarly, the network has begun a program of outreach to other sectors through partnerships with relevant organizations such as individual architecture firms, government agencies (such as the CMHC) and ICT companies. These partnerships are difficult to initiate and do take time to mature. The experience of other mult-sectoral projects, however, shows that they can be extremely valuable.

Interdisciplinarity, however, remains both an opportunity and a challenge. In effect, no single profession or discipline "owns" design - particularly in today's world of contemporary practice where old structures and hierarchies are being eroded by new approaches. New technologies, for example, require the inclusion of computer scientists. Participatory design is predicated on the inclusion of the client and the general public as part of the design team. And design-build projects rearrange the relationship between architect and developer. Real and meaningful collaborations in this new world of design often require adjustments to traditional relationships.

\section{Strategy to Build on Existing Relationships and to Initiate Effective Linkages}

The cornerstone of the network's strategy for relationship building is trust. Over the past few months, this sense of trust has developed among the founding members by valuing and recognizing different points of view and looking for common ground. A similar approach will be used to build new linkages with government agencies, non-governmental organizations and the private sector.

We will plan a selection of theme events in consultation with our partners that will benefit us all. The SmartGeometry initiative is a good illustration of this approach. Workshops have been developed in conjunction with a private sector partner, Bentley Systems. These activities provide a firm grounding in parametric design, a cutting edge theme in design research, and aid in the development of highly qualified personnel. By sharing the costs of such workshops, an effective partnership is built.

The CDRN will build on this simple strategy to develop new linkages as well. What kinds of activities would benefit design associations such as the Royal Architectural Institute of Canada? The best way to answer this question is to work directly with them in their professional development program. Planning with the buy-in of the critical stakeholders is an essential part of the CDRN approach.

In fact, professional development and continuing education are the keys to link with many different organizations and agencies. Almost every such organization today has embarked on such a program and working together to share costs and expertise is an excellent way to build partnerships.

Two key relationships for the CDRN are with the Canadian Design Engineering Network (CDEN), and the NSERC Design Chairs. The former has focused largely on improving the quality of design education in Canada's engineering schools. The latter comprise 
accomplished design engineers focused on improving the level and quality of design engineering activity within Canadian universities (CDE 2005). With its focus on the human issues in design, the CDRN is distinct from both but demonstrates substantial complementarity. The CDRN Network Director (Woodbury) has attended both CDEN conferences to date and has held cordial and focused discussions with key members of CDEN and the NSERC Design Chairs. There appear to be natural opportunities for cooperation, but realizing these will take time. Taken together these three groups begin to be representative of design in Canadian academia. The CDRN views the engineering design enterprise as essential to the success of all design work and a key part of the future of design in Canadian academia. An ongoing part of the CDRN mandate will be to seek opportunities to engage with both CDEN and NSERC Design Chairs, especially, but not limited to, holding theme events in conjunction, association or relation with those of CDEN. At the same time the CDRN provides Canada with an opportunity to elevate the presence of design across all its relevant disciplines and bring these relationships to fruition. Insofar as the CDRN is predicated on an open and inclusive approach to design research it provides a valuable bridge to the design world outside of engineering.

Recognizing that all three organizations value design and see it as a competitive advantage, it essential that they collaborate to create an environment where design and design research can flourish. In particular this means promoting the idea of design as an instrument of public policy to all levels of government. While countries such as China, South Korea and Singapore are developing national design strategies and investing heavily in design ${ }^{\mathrm{i}}$, Canada is doing little in this regard. The CDRN is currently working with the Asia Pacific Foundation to investigate the role of design as an instrument of public policy in Singapore and South Korea and this information will be shared with all stakeholders.

\section{Summary}

It seems clear that in a world where design is becoming more interdisciplinary and more fluid that research must be coordinated and cooperation is essential. The CDRN provides an open and inclusive approach to design research across disciplines that respects and accommodates the concerns, perspectives and methodologies of its various practitioners and receptor communities. It includes representation from both inside and outside the world of design engineering and as such it provides a platform for developing a powerful new model of design research.

\section{References}

${ }^{\mathrm{i}}$ Cox, George. Cox Review of Creativity in Business: Building on the UK's strengths, 2005. Accessed at: www.hmtreasury.gov.uk/independent reviews/cox re view/coxreview index.cfm on June 13, 2006 